\title{
Leveraging the Rhetorical Energies of Machines: COVID-19, Misinformation, and Persuasive Labor
}

\author{
Miles C. Coleman' ${ }^{1}$ \\ 1 Communication Studies, Rowan University, Glassboro, New Jersey, USA
}

\begin{abstract}
The rampant misinformation amid the COVID-19 pandemic demonstrates an obvious need for persuasion. This article draws on the fields of digital rhetoric and rhetoric of science, technology, and medicine to explore the persuasive threats and opportunities machine communicators pose to public health. As a specific case, Alexa and the machine's performative similarities to the Oracle at Delphi are tracked alongside the voice-based assistant's further resonances with the discourses of expert systems to develop an account of the machine's rhetorical energies. From here, machine communicators are discussed as optimal deliverers of inoculations against misinformation in light of the fact that their performances are attended by rhetorical energies that can enliven persuasions against misinformation.
\end{abstract}

Keywords: human-machine communication, rhetoric, rhetorical energy, inoculation theory, COVID-19

\section{Introduction: The Informational and Persuasive Labors of Machine Communicators Amid the Pandemic}

With the COVID-19 pandemic came anxiety-inducing uncertainties (Rettie \& Daniels, 2021), exacerbated by an accompanying "infodemic," shaped not just by a massive surge of information, generated by unprecedented levels of effort to learn about the virus and its spread, but also misinformation (World Health Organization, 2020; Zaracostas, 2020).

CONTACT Miles C. Coleman (D) - Communication Studies • Rowan University • 201 Mullica Hill Rd, Glassboro, NJ 08028 • colemanm@rowan.edu 
Consequently, it makes sense that much of the conversation about machine interlocutors amid the pandemic is focused on relieving humans from an uptick in demand for answersinformational labor. Chatbots, for instance, are identified in the academic literatures as potential means by which to offset the overloading of medical staff by distributing the labor of answering key medical questions across automated, artificially intelligent systems (Battineni et al., 2020; Sezgin et al., 2020) as well as means by which to enhance message cohesion by centralizing information within a single system, rather than across an array of individuals answering questions (Herriman et al., 2020). Machines do not need to sleep, nor do they take on the psychic burdens of relentless interactions with persons who are understandably worried about their place in a world marked by the unpredictability of viral spread and the isolation of preventative lockdown. Machines just "do." As such, machines are conceived as interlocutors well-suited to reducing uncertainty for the people who need it without pushing added burden onto living, breathing humans. These sentiments reverberate in popular discourse of the pandemic as well. Take, for instance, the following, excerpted from a "news-vertising" article published in The Atlantic, which describes the abilities of IBM's proprietary machine interlocutor:

One source of relief for government agencies, healthcare organizations, and academic institutions is coming from IBM's Watson Assistant for Citizens. Watson Assistant for Citizens is an assistant with artificial intelligence that can understand and respond to common questions about COVID-19 on its own. The tool ... leverages current data like guidance from the CDC and local sources, such as links to school closings, news, and state updates. (C. Jones, n.d.)

Feeling overwhelmed with all of the questions? IBM can help! In such discourses, machine communicators are imagined as interactive frequently asked question forums, which can update their answers in real time while delivering them in response to natural language queries, offsetting the informational labor of finding and sharing accurate, reliable information amid the pandemic. In this sense, the focus is on creating timely and accurate machine communicators more than on moving or influential ones. "Masks are currently required in Suffolk county."

With concern to health and science communication, approaching the labors of human-machine communicators as informational largely fits with the assumptions of the deficit model of science communication (e.g., see Simis et al., 2016), wherein if people are engaging in behaviors that do not support public health, it is because they have not yet gotten the scientific facts-they have a deficit of scientific knowledge. And so it goes, this same assumption informs us that we should be focusing on machine communication in a way that supports accurately sharing the latest facts. Of course, timely and accurate facts are important to promoting public health. But, at the same time, such an approach might not go far enough to address the misinformation component of infodemics, wherein persons may very well have access to the facts, but instead choose misinformation that better fits their contexts of interpretation (Del Vicario et al., 2016), and thus they adopt behaviors and beliefs that undermine public health (e.g., refusing to wear a mask in public, or doubting the necessity of vaccination for protecting individual and public health). The problems of infodemics are not merely problems having to do with the exposition of facts; they are also problems having to do with the necessity of persuasion regarding the facts. 
Miner et al. (2020) start to hint at the possibility that persuasive work, not just informational work, can be done by machines with regard to public health during the COVID-19 pandemic. In specific, they briefly proffer the possibilities of machine interlocutors as agents who might solicit more candid responses for symptom tracking, or tap into the power of repetition and step-by-step instruction for influencing individual health behaviors, or even console the lonely amid social isolation by offering ersatz companionship. In these contexts, the focus of the machine communicator is not simply to share accurate and timely information-it is also to persuade users toward positive health outcomes.

In support of such persuasive goals, and specifically for engaging productive persuasions that support public health in the face of misinformation, this article draws on the rhetorical tradition-an approach that is rare in human-machine communication scholarship - to explore the opportunities and threats of persuasion unique to machine communicators as they bear on public health problems, such as the COVID-19 pandemic. In rhetorical studies, there is a growing body of literature that takes machine communication as its object of analysis (e.g., Brock \& Shepherd, 2016; Brown, 2015, 2014; Coleman, 2018, 2020; Hess \& Davisson, 2017; J. Jones \& Hirsu, 2019; K. Kennedy, 2016; Miller, 1978, 2007), interrogating the discourses about, as well as of, machines, helping to better understand machines as socio-historically situated actors that actively participate in meaning-making. However, rhetorical scholarship is seldom in direct conversation with the human-machine communication literature, and vice versa.

In the following sections, I put human-machine communication in conversation with the subfields of digital rhetoric and rhetoric of science, technology, and medicine to think through the rhetorical energies that attend machine interlocutors and the influential resonances of those energies with health and science communication. The article will start first with an operationalization of rhetorical energy as an idea useful for explaining the persuasive work of machine interlocutors beyond surface-level demarcations between technical or human-like performance. From here, Alexa, and the performative similarities that it shares with the Oracle at Delphi are traced to demonstrate that, while the machine is not alive, it nonetheless contributes rhetorical energies, which enliven public health claims by signaling to human concerns in more-than-human ways. Finally, inoculation theory is offered as a means by which to approach the persuasive labors of machines amid an infodemic, while leveraging the rhetorical energies of machine communicators to animate persuasions against misinformation.

\section{The Rhetorical Energies of Machine Communicators}

Rhetoric, for many, is a term that brings to mind such things as "stylistics", and "lines of argument," indicating a realm of scholarship and practice focused on language. Rhetoric is often also conceived as a squarely human enterprise in the sense of being reserved for those entities that can be persuaded just as much as they can persuade others with their eloquence. From this conception of rhetoric, machine communicators might be considered by some as quasi rhetors (rhetorical agents), in the sense of emulating human eloquence, rather than being persuasive in and of themselves, for they lack the capacity to engage genuine symbolic interaction (e.g., see Hepp, 2020). For this reason, one might find it difficult to concede that machine communicators add anything in the way of rhetorical action. If anything, 
human-machine communication might be said to lack that something more found within genuine exchanges between living, breathing persons: "a relationship between two entities who will attribute agency to each other" (Miller, 2007, p. 149, emphasis added; see also, Yang, 2020).

Yet, if we adjust our definition of rhetoric, say, by following George Kennedy (1992) in his proposal to think of rhetoric not as based in language or argument, or even as solely the enterprise of humans, but rather as "the energy inherent in communication" the persuasiveness of machines as machines begins to emerge (p. 2, emphasis added). In defining rhetoric as energy, the locus of rhetoric is found not in language, but in the energy expended and experienced in a given interaction, shaped by biology and culture. Rhetorical energy can include language, but also includes such things as "physical actions, facial expressions, gestures, and signs generally" (p. 4). What makes Kennedy's contribution particularly distinctive is his interrogation of the rhetorics of non-human animals, which are not located in language per se, but rather in performances. Bucks demonstrating their rank in the deer social order via public displays of strength. That is rhetorical energy. Flowers making appeals to honeybees with sweet smells. That is rhetorical energy too. The crux of rhetoric as energy is that it locates influence not in language, or human action, but more broadly in the energies that are "at work" in the interaction between entities.

Relocating influence in this way, as Ingraham (2018) elaborates, jaunts the analyst into "the biologically hardwired realm of pre-intentional survival mechanisms, those that are communicated through a perceivable code, yes, but not necessarily in symbolic messages governed by a semiotic regime of meaning" (p. 262). Put differently, while our visceral responses to the world - and the other entities that imbue it with energy - might be "read," they are also non-conscious, born of entanglements of biology and culture. Although George Kennedy (1992) is largely concerned with the prospect of locating rhetoric in the realm of nonhuman animals, it does not take a large leap to consider that machines, as they pulse electricity and carry out processes, are expending energies, beyond words. When we do, we might recognize that, while machines might not be engaging in genuine symbolic interaction with their human counterparts, they might nonetheless add something persuasive as machines, located not in stylistics or lines of argument per se, but rather in the multisensorial performances of their movements "behind and beyond the screen" (Boyle et al., 2018, p. 255). In a similar manner to what Hawhee (2017) points out in her historical readings of nonhuman animals as they relate to rhetorical practice, machinic performances can be said to "enliven the imagination" (p. 169). Snapping turtles, thrashing sharks, sleeping bears-they provide more, found in the elevation of metaphors, experienced not simply in the mind, but in the body, and in ways that rely on the import of nonhuman rhetorical energies. It is in this way that we can see what rhetorical energy as a term of art reveals in the analysis: while machines are not alive, they nonetheless perform in lively ways, manifesting force as visceral responses entangled with material culture to enliven discourse.

By lively (rather than alive), I mean that the agency of machine communicators can be conceptualized as existing between capacity and effectivity, located not in agents, but rather in performative events (Miller, 2007), instantiating intra-actions, or agential outcomes resulting not from direct human action, but rather from negotiations between humans and nonhumans (Barad, 2007). As Krista Kennedy (2016) succinctly articulates: "Conceptualized as performance rather than as inherent capacity, agency is not a property that a subject 
can possess ... but rather it arises through response to a situation composed of parameters beyond the control of any single actor" (p. 33). While machines may not be invested minds, making appeals to others, they do instantiate performances, intermingling in the wider discourse ecology, moving on their own, reacting to situations, imbuing them with their energies.

Machine communicators, as they move on their own, carry an air, a distinctly nonhuman ethos, located in visceral responses to their movements, entangled with culture. As Miller (1978) has noted, technologies, such as computing machines, are accompanied by an ethos that encourages us "to think them truer, or more transparent, or more objective" precisely because they are meant to remove the human, encouraging an unadulterated experience with the "external world" (p. 236). The movements of computing machines, then, because they derive from developmental traditions of engineering and mathematicsso-called hard-logical realms of knowledge-can afford "the reassurance of forethought, stripped away from the fallibility of the human 'heart' and 'hand"' meaning that machine communicators, while they certainly can imitate human communication, are also attended by (non)human energies, wherein, "science is given 'legs"' (Coleman, 2018, p. 343). So, machine communicators can certainly mime the symbolic interactions of humans, but they do so while also performing as machines attended by energies that interact with human bodies, primed by technoscientific cultural habitus to cultivate visceral feelings, beyond words.

For example, accompanying Alexa's robotic voice response instructing a person that they should seek COVID-19 testing (e.g., see The Mayo Foundation, 2021) are the energies of a computing machine, making real-time application programming interface calls while analyzing user responses in coalition with the Centers for Disease Control and the Mayo Clinic. Such energies, in that they can offer a feeling associated with the "promise of algorithmic objectivity" (Gillespie, 2014, p. 168), are complementary to the scientific-based health claims being made by Alexa. The rhetorical energies of the machine, in other words, support the plea to get tested by resonating with the grander discourses of science, technology, and mathematics, not merely as an idea, but rather as a feeling, entangled with the idea, imbued via the movements of Alexa. In the same way that the timbre of a person's voice and the gesticulation of their body matter to the impact of their utterances in ways enculturated by public life (e.g., learning how to "pick up" on the energies of persons' performances) the computational performance of Alexa matters to its influence. Only, we are unaccustomed to talking about the nonverbal performances of machines, at least in ways that push deeper, beyond the surface.

\section{Going "Deeper" With the Rhetorical Energies of Machines: Toward Anthropromechanation}

In human-computer interaction studies there exists the concept of "automation bias," which designates those moments where persons trust in the conclusions afforded by machine communicators because the machines behave in machine-like ways. Additionally, it is known that the trustworthiness and non-trustworthiness of machines toggle as one differentiates between specific designs of machinic agents and their purposes. That is, if we are designing a machinic agent to be a fun friend, designs that encourage anthropomorphism are likely to enhance user trust. Conversely, if we are designing a machinic agent to act in the stead of an 
expert (e.g., medical doctor or teacher) it is likely that designs that encourage automation bias enhance user trust (Seeger \& Heinzl, 2018). What we learn from this is that neither anthropomorphism nor automation bias is solely sufficient for capturing the influence of machine communication because context matters. Such a realization is supported by studies that test human reactions to robot speech, which demonstrate that humans tend to rate interactions with robots more positively when they are polite. So, for instance, if a robot guard is inspecting peoples' bags, those people might feel less threatened by the robot if it includes niceties - "Please, and thank you"-along with its commands and instructions. Such is an outcome "interpreted as evidence for people expecting robots to be polite in a robotic way” (Meyer et al., 2016, p. 280).

Similarly, analyses of human-human and human-chatbot conversations show that people use more profanity when talking with a chatbot. Specifically, "the greater use of profanity in these conversations suggests that participants never lost sight of the fact that they were communicating with a computer" (Hill et al., 2015, p. 250). What we garner from such studies is that machines, whether they are performing like machines or are performing more like humans, are subject to expectations that are unique to machines, but are nonetheless modulated by the habits of human social interaction, wherein, people "apply a wide range of social rules mindlessly," not because people are thinking about the human in the computer, but rather, they are operating in rote as beings enculturated as human interactants (Nass \& Moon, 2000, p. 93). To read into the rhetorical energies of machines is to employ the interpretive sensibilities of the rhetorical tradition to drive at the otherwise rote, mindless expectations applied to machine communicators, by unpacking the deep ecologies of discourse that shape what "machine-like" means, beyond simply declaring a given performance as robotic or anthropomorphic.

In human-machine communication, Banks \& de Graaf (2020) have made strides to push past the automation/anthropomorphization binary in their proposal for agentagnosticism, which clears space for the idea that machines are not merely media of human communication, for they also contribute to meaning-making (see also Gunkel, 2012; Guzman \& Lewis, 2020). Specifically, the agent-agnostic model: “(1) considers each agent's functions in the process (with attention to functions that may not be directly observable) and (2) draws on literatures pertaining to those functions (independent of enacting agent) to consider how meaning may emerge through antecedents, processes, and effects of that function" (Banks \& de Graaf, 2020, p. 26). Interrogating the rhetorical energies of machine communicators is to take up an agent-agnostic approach while placing special attention on the antecedents of discourse and materiality that are entangled with the multisensorial performances of machines, which may not be directly observable, but which are nonetheless present. Masculine hegemony, I-Robot, the Oracle of Delphi, the physical properties of electricity, and the evolution of the software ecology-such discourses and material realities interact to inform the energies of machinic performance. Orienting to these ambient features is to attune to those human (and nonhuman) actants that work together to shape the lifeworlds in which the rhetorical energies of machines emerge (Rickert, 2013). Rhetorical energy is a means by which to dive deeper-to go beyond the surface-level automation/ anthropomorphization binary_by recognizing that, while machines might not "believe" or "feel," they nonetheless contribute energies, which can enliven human discourses in morethan-human ways. 


\section{Enlivening Human-Machine Communication With Rhetorical Energies: Alexa and the Oracle of Delphi}

Where much of the conversation about machine-communicators in public health contexts tends to focus on their abilities to deliver accurate and valid information regarding, for example, resources for addiction (Nobles et al., 2020) or information about vaccination (Alagha \& Helbing, 2019), existing work in human-machine communication starts to move toward the idea that machine communicators might also be contributors of persuasive labor. For example, it has been shown that, in public health contexts, like sexually communicable disease messaging, persons can perceive the quality of Twitter bots as roughly equivalent to human communication concerning credibility, attractiveness, communication competency, and interactiveness (Edwards et al., 2014). Locating the rhetorical energies of machines takes this a step further to ask whether machine interlocutors as machines, might also bring something more than mere human or technical performance.

At the surface level, for instance, the plea of Alexa to the human to seek testing for COVID-19 seems to leverage automation bias to garner trust in its claim. But, if we were to dive deeper, we might consider the longstanding trope of the prophet, and the emergence of modern scientific forecasting and interpretation into existing cultural grooves of discourse previously etched from millennia of looking to oracles, augers, and seers for answers (Walsh, 2013), and how this trope interacts with the phenomenon of "knowledge-based systems," or as they are more commonly called, expert systems (Akerkar \& Sajja, 2010). Expert systems (e.g., analysis tools for modeling chemical compounds, climate forecasting, and medical diagnosis) operate from knowledge-bases, most commonly derived from the efforts of experts, and inference engines, sets of logical procedures programmed into the system for retrieving information from the knowledge-base. Expert systems have emerged as nodal points of interaction, characterized by rituals, born of the work of software engineers and scientific experts, to better interpret and make truths beyond the limits of human perception, which further resonates with the trope of the prophet.

For example, in the ancient Greek ritual of Delphic divination, the Pythia, also known as the Oracle of Delphi, was a position filled by the "rulers of the oracle" who would select "a virtuous woman of the lower classes" (Farnell, 1907, p. 189). The Pythia would inhale divine vapors as they rose from a fissure in the Temple of Apollo, impelling her to speak as a medium, manically echoing the truths of the aether, which would then be interpreted into prophecy (p. 189). The Pythia was treated as a portal to the aether-a conduit to truth. When she spoke, her words were attended by rhetorical energies, perceptible as movement and prosody, ambiently entangled with cultural practice, which signaled to human concerns in more-than-human ways. The Oracle was a human, who spoke as a human, imbued with the vibratory rhetorical energies of the divine. Of course, with the passing of time, our paradigms of knowledge-making have shifted in aspiration, represented in movements away from rituals of superstition, and toward rituals of scientific observation and datadriven analysis. Despite the shift in ritual, though, the role of prophecy remains. Instead of leveraging the divine vapors, and the Oracle of Delphi herself, as "technologies of prophecy," we increasingly turn to computing technologies as means by which to see beyond the human, to visualize and make sense of otherwise imperceptible data, such as that involved in climate change modeling (Walsh, 2013, p. 165). Expert systems, while they very well can 
possess scientific knowledge, also emerge as integral technologies of prophecy, which participate in our modern discourses not merely by satiating our cerebral needs for data, but also our embodied needs for reassurance-to feel like we "know."

Alexa, in that it is a system that has a knowledge-base and an inference engine is technically an expert system. But, interestingly it is also one that shares characteristics with the Oracle of Delphi. Alexa is not a technology of prophecy exclusively entitled to the prophets of science (i.e., experts); it is more accessible to persons across levels of intellectual initiation and class divides. Coupled with the fact that Alexa performs as female, and one who might even be characterized as "virtuous," at least in the chaste sense that the ancients probably meant it, further alludes to a deep resonance with the Delphic rituals of yore and the modern rituals of expert systems (and all of the patriarchal and elitist baggage that comes with; e.g., see Woods, 2018). Alexa, moreover, is a machine communicator, characterized by a rhetorical energy that resonates with grander discourses of science, technology, and medicine entangled with the trope of the prophet, emerging as an oracle for patrons to solicit insight from the aether, affording a semblance of stable knowledge amid a moment characterized by uncertainties and unknowns, manifest as a visceral feeling, offered by its performance as a machine signaling to human concerns in more-than-human-ways.

Supporting Alexa's oracle-esque energy is the networked nature of its communication. That is, while a given "skill" (an application programmed into the Alexa framework) might entail a specific, closed knowledge-base (e.g., the currently known symptoms of COVID19 as curated by the Mayo Clinic), the system itself is more broadly networked to many knowledge-bases, including, for instance, Wikipedia, the web-based encyclopedia, selfproclaimed as an open collaboration aimed at the goal to "create a world in which everyone can freely share in the sum of all knowledge" ("Wikipedia:About," 2021). It is in this sense that the rhetorical energies of Alexa are manifold, entwined in an ambient infrastructure and manifest in its movements as a machine, offering a nodal flash in which Alexa's grander network of actants is invoked as an "inventional resource" (Besel, 2011, p. 122) composed of electricity, wires, software ecologies, organizational images, as well as public imaginings, characterized by long-seated socio-historical happenings, myths, metaphors, and rituals. "You should wear a mask to protect yourself and others."

Is Alexa convincing because it solicits automation bias? Probably. But, it is also convincing because it moves with the energies of an oracle, directly wired into the info-sphere, affording a glimpse into the aether, offering a conversation that feels like shaking the bones-to foresee-amid a global pandemic fraught with anxiety-inducing uncertainty. Alexa and the impact of its utterances is not straightforwardly a matter of technical features or human-esque behavior-it is also a matter of historical grooves of discourse, punctuated by technoscientific assumptions, and the contemporary public imagination of health.

As with any other sort of rhetoric, the rhetorical energies of machine communicators are not intrinsically fixed to the facts. In the context of public health, leveraging the rhetorical energies of machines is a tactic that can be employed to undermine public health, just as much as it can be employed to support it. Where the example of Alexa above is leveraging a machinic rhetorical energy that resonates with the trope of the prophet to support appeals to protect public health, that same energy can also undermine public health by playing into discourses that facilitate conspiratorial denials of health science, further underscoring the persuasive labors of which machines are capable. For example, a dispelled 
piece of misinformation, appearing in a TikTok video, shared as a Facebook post, exhibits Alexa answering the question, "Alexa, did the government release the coronavirus?" to which Alexa responds, "According to Event 201, the government planned this event, created the virus and had a simulation of how the countries would react. This simulation occurred October 18, 2019. The government released the virus among the population and has lost control of the outbreak" (cited in Orsagos, 2020). Based on recreations of the question posed to Alexa, and on statements from Amazon, the question and answer have been deemed a hoax (Orsagos, 2020). Some have conjectured that Alexa was pre-programmed to respond in the way that it did. But, why would someone do that? The answer is in the rhetorical energy that Alexa affords. Rather than making a traditional "tinfoil hat" post to Facebook, the creator of this video has created a machinic performance, which leverages the rhetorical energies of Alexa to afford not just a technical credibility, but also an affective potency, resonant with the trope of the prophet as it is smashed in with the suspicions of COVID19 pandemic conspiracy theorists and technoscientific ritual. Machinic performances, and the energies that attend them, moreover, are not bound to the "objectivity" of science and mathematics that we often equate with them-they can be leveraged in ways that construct truthiness and legitimacy, even for claims that are untrue.

What we realize from this is that, alongside being a resource for enacting informational labor amid public health crises like the COVID-19 pandemic, machine communicators are also emerging as unique resources of persuasive labor, characterized by machinic rhetorical energies, which can be leveraged to promote or undermine public health.

\section{Enlivening Inoculations Against Misinformation With Machinic Rhetorical Energies}

The notion that machine communicators are emerging as a means for science denialists to circulate misinformation is underscored by Amazon's implementation of a policy to remove and restrict COVID-19 Alexa skills during the pandemic (Schwartz, 2020). Alongside this, according to Tom Taylor, senior vice president of the Alexa unit, with concern to the use of the voice-based assistant amid the pandemic, "We've seen a huge increase in the use of voice in the home" (cited in Soper, 2020). The machine interlocutor, then, seems to present itself as an opportunity to counteract misinformation amid infodemics, and in ways that can leverage not only the affordances of automation but also the rhetorical energies of machine communicators to do more than share accurate and timely facts. Inoculation theory offers one route for doing just that.

Inoculation theory operates on the assumption that giving weakened versions of misleading information will activate a response "that is analogous to the cultivation of "mental antibodies, rendering the person immune to (undesirable) persuasion attempts" (McGuire, 1961; van Der Linden \& Roozenbeek, 2020, p. 152). Since its inception in the early 1960s, the idea has been repeatedly tested and studied, demonstrating that inoculation works to protect people from being persuaded by misinformation. For example, according to Banas \& Rains's (2010) meta-analysis of over 40 years of inoculation theory studies: "Even with a concerted effort to avoid publication bias and the possibility of inflated effects, the data revealed inoculation treatments are superior at conferring resistance when compared to 
both no-treatment control and supportive treatments" (p. 305; see also, Compton et al., 2016).

Inoculation messages require two ingredients. The first is an (implied or directly stated) threat, and the second is a counterargument against (or refutation of) misinformation (Compton, 2013; Compton \& Pfau, 2009; McGuire, 1964). The following is an example of an inoculation message, which includes a direct statement of threat in the form of a warning, alongside a refutation:

Warning: "Some politically motivated groups use misleading tactics to try to convince the public that there is a lot of disagreement among scientists."

Refutation: "However, scientific research has found that among climate scientists, there is virtually no disagreement that humans are causing climate change." (van der Linden et al., 2017, p. 3)

These two-part messages induce a threat response to the warning, which activates the body (one's feelings), motivating learning from the counterargument. In this sense, and as is supported by the literature, both components (the threat and the counterargument) need to be present for inoculation to occur (e.g., see van der Linden et al., 2017). Inoculation messages, because they can be formulated into discrete warning/refutation messages, triggered by specific keywords of misinformation, lend themselves to being automated into the communicative repertoire of machine communicators. Coupled with this is the important factor of inoculation "decay," which means that the protective effects of an inoculation message get weaker over time (Maertens et al., 2020; Maertens et al., 2021; Pfau \& Burgoon, 1988). Inoculation constancy is an outcome achievable with automation. Machine communicators, moreover, are means by which to follow up with "booster" messages to maintain protection from misinformed persuasions.

Where inoculation might largely be conceived as a prophylactic measure-that is, a measure meant to avoid infection - there is growing interest in, and evidence for, pursuing the therapeutic uses of inoculation as a means of un-infecting misinformed persons (Compton, 2020; van der Linden \& Roozenbeek, 2020; Wood, 2007). Put differently, inoculation can protect people from being persuaded by misinformation. But, we are also learning that it might also help to undo the effects of misleading information. Concurrent to this, active inoculation has been proposed as an approach that does not necessarily focus on subject-specific misinformation (e.g., COVID-19 conspiracies, or vaccine denialism), but rather the techniques of misinformation broadly. This form of inoculation is meant to equip persons to better sift through ulterior motives and slights of hand when they are presented as "facts" by actively engaging with those techniques, by, for instance, playing a video game to spot fake news (Basol et al., 2020; van der Linden et al., 2020).

Consequently, inoculation presents a means by which to reconceptualize the labors of machine communicators amid an infodemic beyond the deficit model of science communication. This could entail including, right alongside the accurate and timely facts, inoculation messages, ported to instances of misinformation, built into two-part (warning and counterargument) messages, delivered prophylactically to keywords of public health, and therapeutically to keywords of misinformation-persuasions as well as facts. But it could also 
involve more interactive experiences meant to inoculate by encouraging users to actively engage the techniques of misinformation, wherein the machine might be leveraged to periodically "check in" with users, offering them a quick game of spot the fake news. Moreover, delivering inoculation messages via the machine might be optimal, because of its attending rhetorical energies. By engaging inoculative messaging with a machine interlocutor, like Alexa, one can say that the machine is doing more to enact the persuasive labors necessitated by an infodemic, while, at the same time, augmenting with a potent feeling entangled with the discourses of expert systems as they resonate with the trope of the prophet.

\section{Conclusion}

Despite the dominant imaginings of machine communicators as well-suited for engaging informational labor amid crises, we must recognize that they are also capable of persuasive labor, which can promote or undermine public health. Here, I have suggested inoculation theory as a means for leveraging the persuasive labors of machines amid infodemics, for inoculation messages lend themselves to being automated, and automation itself affords a route to inoculation constancy, supporting sustained immunity to misleading persuasions. Beyond this, I have suggested that the performances of machine communicators are attended by rhetorical energies, which can enliven their persuasions against misinformation, illustrating that perhaps they are optimal agents for taking up that work.

Social scientific questions are raised by the current discussion. Do inoculations, perceived as originating from machines, have more or less potent effects than those perceived to originate from persons? What do the decay effects of inoculation interventions look like in cases where constancy is added by the machine? Are there differences in the effects of prophylactic engagements and therapeutic engagements wagered by machines? Does interactivity matter to either prophylactic or therapeutic interventions? On par, questions for interpretive scholars are also raised. I have developed an account of the rhetorical energies of Alexa's machinic performance as it bears on public health discourse. But, are there other accounts of rhetorical energy that help to understand machinic performances in contexts beyond health and science (e.g., art or politics)? What tactics of leveraging the rhetorical energies of machines emerge in those contexts?

The discussion of this article, in that it draws on rhetorical scholarship to explore the persuasive threats and opportunities of machine communicators amid infodemics, highlights the value-added of interpretive approaches to human-machine communication: to read deeply, beyond the surface. But, because many of the learning moments arrived at in this article are derived not from interpretive or social scientific perspectives, but rather, between them, I am hopeful that scholars of human-machine communication will consider putting their work in conversation with existing rhetorical work on machine communicators, and vice versa. Doing so can only be generative, for as we are learning from the pandemic, machine communicators and their relations to communicative practice, evolve, emerge, and metamorphize in unexpected ways. Moving toward more holistic accounts of machine communication, either through cross-citation or in full-out collaborations across epistemologies, is a means for accounting for the human experience as we increasingly negotiate it with machines during, and beyond, the COVID-19 pandemic. 


\section{Author Biographies}

Miles Coleman is an assistant professor of Communication Studies at Rowan University. He studies rhetoric of science, digital rhetoric, and communication ethics. His research appears in such journals as Philosophy \& Rhetoric, Review of Communication, First Monday, Journal of Media Ethics, Journal of Aesthetics \& Culture, and Western Journal of Communication, among others.

https://orcid.org/0000-0002-5321-7997

\section{References}

Akerkar, R., \& Sajja, P. (2010). Knowledge-based systems. Jones \& Bartlett Publishers. https://web.archive.org/web/20210326182522/https://www.jblearning.com/catalog/ productdetails/9780763776473

Alagha, E. C., \& Helbing, R. R. (2019). Evaluating the quality of voice assistants' responses to consumer health questions about vaccines: An exploratory comparison of Alexa, Google Assistant and Siri. BMJ Health \& Care Informatics, 26(1:e100075), 1-6. https:// doi.org/10.1136/bmjhci-2019-100075

Banas, J. A., \& Rains, S. A. (2010). A meta-analysis of research on inoculation theory. Communication Monographs, 77(3), 281-311. https://doi.org/10.1080/03637751003758193

Banks, J., \& de Graaf, M. (2020). Toward an agent-agnostic transmission model: Synthesizing anthropocentric and technocentric paradigms in communication. Human-Machine Communication, 1(1), 19-36. https://doi.org/10.30658/hmc.1.2

Barad, K. (2007). Meeting the universe halfway: Quantum physics and the entanglement of matter and meaning. Duke University Press. https://doi.org/10.2307/j.ctv12101zq

Basol, M., Roozenbeek, J., \& van der Linden, S. (2020). Good news about bad news: Gamified inoculation boosts confidence and cognitive immunity against fake news. Journal of Cognition, 3(1), 1-9. https://doi.org/10.5334/joc.91

Battineni, G., Chintalapudi, N., Amenta, F. (2020). AI chatbot design during an epidemic like the novel coronavirus. Healthcare, 8(2), 1-8. https://doi.org/10.3390/healthcare8020154

Besel, R. D. (2011). Opening the "black box" of climate change science: Actor-network theory and rhetorical practice in scientific controversies. Southern Communication Journal, 76(2), 120-136. https://doi.org/10.1080/10417941003642403

Boyle, C., Brown Jr, J. J., \& Ceraso, S. (2018). The digital: Rhetoric behind and beyond the screen. Rhetoric Society Quarterly, 48(3), 251-259. https://doi.org/10.1080/02773945.20 18.1454187

Brock, K., \& Shepherd, D. (2016). Understanding how algorithms work persuasively through the procedural enthymeme. Computers and Composition, 42, 17-27. https:// doi.org/10.1016/j.compcom.2016.08.007

Brown, J. J. (2015). Ethical programs: Hospitality and the rhetorics of software. University of Michigan Press. https://doi.org/10.1353/book.42619

Brown J. J. (2014). The machine that therefore I am. Philosophy \& Rhetoric, 47(4), 494-514. https://doi.org/10.5325/philrhet.47.4.0494 
Coleman, M. C. (2018). Machinic rhetorics and the influential movements of robots. Review of Communication, 18(4), 336-351. https://doi.org/10.1080/15358593.2018.1517417

Coleman, M. C. (2020). Comparative rhetorics of technology and the energies of ancient Indian robots. In K. Lloyd (Ed.), Handbook on comparative rhetoric. Routledge. https:// doi.org/10.4324/9780367809768-1

Compton, J. (2013). Inoculation theory. In J. P. Dillard \& L. Shen (Eds.), The SAGE handbook of persuasion: Developments in theory and practice (2nd ed.). SAGE. https://doi. org/10.4135/9781452218410

Compton, J. (2020). Prophylactic versus therapeutic inoculation treatments for resistance to influence. Communication Theory, 30(3), 330-343. https://doi.org/10.1093/ct/qtz004

Compton, J., Jackson, B., \& Dimmock, J. A. (2016). Persuading others to avoid persuasion: Inoculation theory and resistant health attitudes. Frontiers in Psychology, 7:122, 1-9. https://doi.org/10.3389/fpsyg.2016.00122

Compton, J., \& Pfau, M. (2009). Spreading inoculation: Inoculation, resistance to influence, and word-of-mouth communication. Communication Theory, 19(1), 9-28. https://doi. org/10.1111/j.1468-2885.2008.01330.x

Del Vicario, M., Bessi, A., Zollo, F., Petroni, F., Scala, A., Caldarelli, G., Stanley, E. H., \& Quattrociocchi, W. (2016). The spreading of misinformation online. Proceedings of the National Academy of Sciences, 113(3), 554-559. https://doi.org/10.1073/pnas.1517441113

Edwards, C., Edwards, A., Spence, P. R., \& Shelton, A. K. (2014). Is that a bot running the social media feed? Testing the differences in perceptions of communication quality for a human agent and a bot agent on Twitter. Computers in Human Behavior, 33, 372-376. https://doi.org/10.1016/j.chb.2013.08.013

Farnell, L. R. (1907). The cults of the Greek states (Vol. IV). Oxford at the Clarendon Press.

Gillespie, T. (2014). The relevance of algorithms. In T. Gillespie, P. J. Boczkowski, \& K. A. Foot (Eds.), Media technologies: Essays on communication, materiality, and society. MIT Press. https://doi.org/10.7551/mitpress/9780262525374.001.0001

Gunkel, D. J. (2012). Communication and artificial intelligence: Opportunities and challenges for the 21st century. Communication+1 1(1:1), 1-25. https://doi.org/10.7275/ R5QJ7F7R

Guzman, A. L., \& Lewis, S. C. (2020). Artificial intelligence and communication: A HumanMachine Communication research agenda. New Media \& Society, 22(1), 70-86. https:// doi.org/10.1177/1461444819858691

Hawhee, D. (2017). Rhetoric in tooth and claw: Animals, language, sensation. University of Chicago Press. https://doi.org/10.7208/chicago/9780226398204.001.0001

Hepp, A. (2020). Artificial companions, social bots, and works bots: Communicative robots as research objects of media and communication studies. Media, Culture, \& Society 42(7-8), 1410-1426. https://doi.org/10.1177/0163443720916412

Herriman, M., Meer, E., Rosin, R., Lee, V., Washington, V., \& Volpp, K. G. (2020, June 18). Asked and answered: Building a chatbot to address Covid-19-related concerns. NEJM Catalyst Innovations in Care Delivery. https://catalyst.nejm.org/doi/full/10.1056/ CAT.20.0230

Hess, A., \& Davisson, A. (Eds.). (2017). Theorizing digital rhetoric. Routledge. https://doi. org/10.4324/9781315203645 
Hill, J., Ford, W. R., \& Farreras, I. G. (2015). Real conversations with artificial intelligence: A comparison between human-human online conversations and human-chatbot conversations. Computers in Human Behavior, 49, 245-250. https://doi.org/10.1016/j. chb.2015.02.026

Ingraham, C. (2018). Energy: Rhetoric's vitality. Rhetoric Society Quarterly, 48(3), 260-268. https://doi.org/10.1080/02773945.2018.1454188

Jones, C. (n.d.). Meet "Watson," the AI chatbot answering coronavirus questions. The Atlantic. https://web.archive.org/web/20210326175407/https://www.theatlantic.com/ sponsored/salesforce-2020/IBM/3391/

Jones, J., \& Hirsu, L. (Eds). (2019) Rhetorical machines: Writing, code, and computational ethics. University of Alabama Press.

Kennedy, G. A. (1992). A hoot in the dark: The evolution of general rhetoric. Philosophy \& Rhetoric, 25(1), 1-21. https://www.jstor.org/stable/40238276

Kennedy, K. (2016). Textual curation: Authorship, agency, and technology in Wikipedia and Chambers's Cyclopoedia. University of South Carolina Press. https://doi.org/10.2307/j. ctv6wgmzj

Maertens, R., Anseel, F., \& van der Linden, S. (2020). Combatting climate change misinformation: Evidence for longevity of inoculation and consensus messaging effects. Journal of Environmental Psychology, 70, 101455, 1-11. https://doi.org/10.1016/j. jenvp.2020.101455

Maertens, R., Roozenbeek, J., Basol, M., \& van der Linden, S. (2021). Long-term effectiveness of inoculation against misinformation: Three longitudinal experiments. Journal of Experimental Psychology: Applied, 27(1), 1-16. https://doi.org/10.1037/xap0000315

The Mayo Foundation for Medical Education and Research. (2021). Skills from Mayo Clinic. Mayo Clinic. https://web.archive.org/web/20210325132431/https://www.mayoclinic.org/ voice/apps

McGuire, W. J. (1961). The effectiveness of supportive and refutational defenses in immunizing and restoring beliefs against persuasion. Sociometry, 24(2), 184-197. https://doi. org/10.2307/2786067

McGuire, W. J. (1964). Inducing resistance to persuasion: Some contemporary approaches. In L. Berkowitz (Ed.), Advances in experimental social psychology. Academic Press. https://doi.org/10.1016/s0065-2601(08)x6005-8

Meyer, J., Miller, C., Hancock, P., de Visser, E. J., \& Dorneich, M. (2016). Politeness in machine-human and human-human interaction. Proceedings of the Human Factors and Ergonomics Society Annual Meeting, 60(1), 279-283. https://doi. org/10.1177/1541931213601064

Miller, C. R. (1978). Technology as a form of consciousness: A study of contemporary ethos. Central States Speech Journal, 29(4), 228-236. https://doi.org/10.1080/105109 77809367983

Miller, C. R. (2007). What can automation tell us about agency? Rhetoric Society Quarterly, 37(2), 137-157. https://doi.org/10.1080/02773940601021197

Miner, A. S., Laranjo, L., \& Kocaballi, A. B. (2020). Chatbots in the fight against the COVID19 pandemic. npj Digital Medicine, 3, Article 65 https://doi.org/10.1038/s41746-0200280-0 
Nass, C., \& Moon, Y. (2000). Machines and mindlessness: Social responses to computers. Journal of Social Issues, 56(1), 81-103. https://doi.org/10.1111/0022-4537.00153

Nobles, A. L., Leas, E. C., Caputi, T. L., Zhu, S. H., Strathdee, S. A., \& Ayers, J. W. (2020). Responses to addiction help-seeking from Alexa, Siri, Google Assistant, Cortana, and Bixby intelligent virtual assistants. npj Digital Medicine, 3, Article 11. https://doi. org/10.1038/s41746-019-0215-9

Orsagos, P. (2020, April 16). No, Amazon's Alexa doesn't say 'the government' planned the coronavirus pandemic. Politifact. https://web.archive.org/web/20210326180010/https:// www.politifact.com/factchecks/2020/apr/16/facebook-posts/no-amazons-alexa-doesntsay-government-planned-cor/

Pfau, M., \& Burgoon, M. (1988). Inoculation in political campaign communication. Human Communication Research, 15(1), 91-111. https://doi.org/10.1111/j.1468-2958.1988. tb00172.x

Rettie, H., \& Daniels, J. (2021). Coping and tolerance of uncertainty: Predictors and mediators of mental health during the COVID-19 pandemic. American Psychologist, 76(3), 427-437. http://dx.doi.org/10.1037/amp0000710

Rickert, T. (2013). Ambient rhetoric: The attunements of rhetorical being. University of Pittsburgh Press. https://doi.org/10.2307/j.ctt5hjqwx

Schwartz, E. H. (2020, March 17). EXCLUSIVE: Amazon Alexa has removed coronavirus skills and won't approve new ones. VoiceBot. https://web.archive.org/ web/20210326180507/https://voicebot.ai/2020/03/17/amazon-alexa-is-removing-andlimiting-coronavirus-skills/

Seeger, A., \& Heinzl, A. (2018). Human versus machine: Contingency factors of anthropomorphism as a trust-inducing design strategy for conversational agents. In F. D. Davis, R. Riedl, J. vom Brocke, P. Léger, \& A. B. Randolph (Eds.), Lecture notes in information systems and organization 25. Springer International. https://doi.org/10.1007/978-3-31967431-5_15

Sezgin, E., Huang, Y., Ramtekkar, U., \& Lin, S. (2020). Readiness for voice assistants to support healthcare delivery during a health crisis and pandemic. npj Digital Medicine, 3, Article 122. https://doi.org/10.1038/s41746-020-00332-0

Simis, M. J., Madden, H., Cacciatore, M. A., \& Yeo, S. K. (2016). The lure of rationality: Why does the deficit model persist in science communication? Public Understanding of Science, 25(4), 400-414. https://doi.org/10.1177/0963662516629749

Soper, T. (2020, June 25). Amazon Alexa leader: COVID-19 has sparked "a huge increase in the use of voice in the home." GeekWire. https://web.archive.org/web/20210326180746/ https://www.geekwire.com/2020/amazon-alexa-leader-covid-19-sparked-huge-increaseuse-voice-home/

van der Linden, S., Leiserowitz, A., Rosenthal, S., \& Maibach, E. (2017). Inoculating the public against misinformation about climate change. Global Challenges, 1(2:1600008), 1-7. https://doi.org/10.1002/gch2.201600008

van der Linden, S., and Roozenbeek, J. (2020). Psychological inoculation against fake news. In R. Greifenader, M. Jaffé, E. Newman, and N. Schwarz (Eds.), The psychology of fake news: Accepting, sharing, and correcting misinformation. Psychology Press. https://doi. org/10.4324/9780429295379 
van der Linden, S., Roozenbeek, J., \& Compton, J. (2020). Inoculating against fake news about COVID-19. Frontiers in Psychology, 11, Article 566790. https://doi.org/10.3389/ fpsyg.2020.566790

Walsh, L. (2013). Scientists as prophets: A rhetorical genealogy. Oxford University Press. https://doi.org/10.1093/acprof:oso/9780199857098.001.0001

Wikipedia:About. (2021, March 11) In Wikipedia. https://web.archive.org/web/ 20210326181645/https://en.wikipedia.org/w/index.php?title=Wikipedia3AAbout\&oldid= 1011466045

Wood, M. L. (2007). Rethinking the inoculation analogy: Effects on subjects with differing preexisting attitudes. Human Communication Research, 33(3), 357-378. https://doi. org/10.1111/j.1468-2958.2007.00303.x

Woods, H. S. (2018). Asking more of Siri and Alexa: Feminine persona in service of surveillance capitalism. Critical Studies in Media Communication, 35(4), 334-349. https://doi. org/10.1080/15295036.2018.1488082

World Health Organization. (2020, April 15). Coronavirus disease 2019 (COVID-19) situation report-86. https://web.archive.org/web/20210308172123/https://www.who.int/ docs/default-source/coronaviruse/situation-reports/20200415-sitrep-86-covid-19.pdf?s fvrsn=c615ea20_6

Yang, M. (2020). Painful conversations: Therapeutic chatbots and public capacities. Communication and the Public, 5(1-2), 35-44. https://doi.org/10.1177/2057047320950636

Zarocostas, J. (2020). How to fight an infodemic. The Lancet, 395(10225), 676. https://doi. org/10.1016/S0140-6736(20)30461-X 